\title{
The Impact Of Consolidation And Strategic Considerations In The Motorcoach Industry
}

Kathryn J. Ready, (Email: kready@uwec.edu), University of Wisconsin-Eau Claire

\begin{abstract}
Little has been written about the motorcoach industry, an industry that is largely comprised of small family-run businesses, and an industry that has witnessed a changed competitive environment during the late 1990's and early 2000's due to the impact of consolidation. In this paper, the author (an insider to the industry) discusses the motorcoach industry and the effect of consolidators. Using survey data drawn from163 motorcoach owner/operators from across the country in early 2002, the author discusses the rising insurance cost crisis as the major concern by many operators in the industry. The link between consolidation effects and insurance costs are examined. From this analysis, strategic considerations for motorcoach owner/operators to ensure future viability are provided.
\end{abstract}

\section{Introduction}

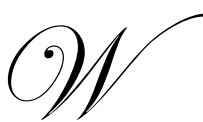

e are an increasingly mobile society as was evinced by the financial impact of September 11 on the travel industry. While the airlines received a timely bailout to help subsize their losses, other sectors of the transportation industry were not covered. One of the most widely used modes of transportation, and one that did not receive bailout funding, are motorcoaches. In the U.S., motorcoaches carried an estimated 774 million passengers in 1999, compared with 568 million by commercial air carriers, and 377 million by commuter rail and Amtrak (ABA, 2000). Motorcoaches are primarily used for travel by five major groups: tour groups, educational institutions, corporations, seniors, charter groups and commuters.

Despite widespread usage of motorcoaches by many diverse groups, little has been written on the industry itself or the issues facing it. This may be primarily because the industry is comprised of small, privately owned family run businesses. During the late 1990's, many changes were occurring which had tremendously negative effects on the industry. Consolidation was a threat to many independents. Revenue was flat, new equipment costs were escalating and overcapacity in the market was becoming commonplace. Marketing was a virtually unknown concept with owners adopting an order-taking approach rather than marketing their business. Low entry barriers encouraged small, inexperienced players to join. Lending companies encouraged new entrants and rapid growth with comparatively easy financing terms resulting in increased sales of new equipment. Motorcoaches were viewed by many customers as a commodity with price the major distinguishing factor. When the total operating costs were finally realized by the new entrants, companies couldn't afford the payments and repossessions became commonplace leading to an oversupply in the industry.

In this paper, I first provide an overview of the motorcoach industry and discuss the effect of consolidators in a changed competitive environment. Next, analysis of the industry is supplemented with actual survey results from 163 owner/operators in the industry that show that the insurance cost crisis is the operators major concern. The relationship between consolidator effects and insurance costs is examined. Finally, strategies for future viability are provided.

Readers with comments and questions are encouraged to contact the author via email. 


\section{Overview of the Motorcoach Industry}

The motorcoach industry is comprised of three major business segments. The largest segment, charter work, which is moving people from point to point, comprises $72 \%$ of the business, yet represents the lowest margin business. Line haul (e.g., designated routes from city to city or to airport terminals) represents $18 \%$ of all motorcoach business and tour groups comprise $10 \%$ of the motorcoach business. Recently, the demand for motorcoach tours has fallen while the demand for line hauls has risen, yet few owner/operators are involved in line haul business. Only $12 \%$ of the companies are involved in line hauls, whereas almost $96 \%$ of the motorcoach companies are involved in charter operations (i.e., the hiring of a motorcoach for a specific group). Those companies operating routes utilize approximately 8,000 to 10,000 motorcoaches and account for 50 percent of all motorcoach mileage (UMA, 2001b).

The motorcoach market is made up of two basic groups: the independents (private owner/operators) and the consolidators. In a 2000 Survey conducted by R. L. Banks \& Associates, the motorcoach industry was estimated to be comprised of about 4,000 companies and about 10 percent of those are based in Canada (Schulz, 2001). These companies operate approximately 44,000 buses. The companies in the industry range from very small privately held companies with fewer than 5 motorcoaches to the largest consolidator with almost 3700 motorcoaches. About ninety percent of the industry is comprised of small businesses operating fewer than 25 motorcoaches. These companies operate about 19,000 buses or about 40 percent of the total fleet and account for almost 40 percent of the total industry mileage. It is estimated that almost half of the industry (i.e., 2000 companies) operates with fewer than 5 motorcoaches and $65 \%$ of the companies are operating with fewer than 10 buses (ABA, 2000).

The mid-sized companies are comprised of approximately 320 companies that run between 25 and 99 buses each. These companies operate approximately 14,000 buses or one-third of the total fleet and account for one-third of the industry mileage. The large companies in the industry are represented by 50 companies that operate more than 100 buses (ABA, 2000). The top 50 companies had total buses in 2001 of 19,047, but the total had fallen to 14,007 by the beginning of 2002 (Starcic, 2002). The largest companies operate about 11,000 buses or about onefourth of the fleet and account for 30 percent of the total industry mileage (ABA, 2000).

Three consolidators are key players in the industry. Coach USA has 3685 motorcoaches (Starcic, 2002) and is comprised of 188 companies representing $10 \%$ of the motorcoach business. Laidlaw Greyhound owns 2775 motorcoaches (Starcic, 2002) and is predominantly a line haul company with less that $1 \%$ of their business generated by tours and charters. VEC Tours has 870 motorcoaches (Starcic, 2002) and represents 1\% of the motorcoach business with 16 companies. All three companies have attempted to carve out a niche in the industry in which they could maximize their efficiencies obtained by their size and geographic presence. The presence of the consolidators has led to strategic changes occurring throughout the industry.

\section{Motorcoach Industry Consolidators}

\subsection{Coach USA}

The largest consolidator in the motorcoach industry is Coach USA. Coach USA began in 1995 by a Houston venture capital firm and went public in 1996 posting a revenue of $\$ 185$ million in that year. In less than three years, Coach USA became the U.S.'s largest provider of motorcoach charters, tour and sightseeing services. Fortyfive percent of the company's business is in tour charters with the remainder divided among corporate contract bus service, scheduled bus services, shuttles and taxicabs. Their business includes non-municipal/commuter/transit motor coach services and (airline) passenger ground transportation service. Today, Coach USA operates in more than 120 cities, and 35 states, provinces and territories in the U.S., Canada and Mexico (www.stagecoachplc.com/corporate/northamerica.html). Coach USA is headquartered in Houston, Texas with regional offices across the U.S. that make purchasing and revenue decisions in order to coordinate the operations within the company. 
During the late 1990s, many analysts were critical of Coach's fast acquisition strategy. Coach USA was not particularly selective in their purchases according to some analysts in the industry and sought rapid geographic coverage at the expense of a well-planned strategy (Culbertson, 1998). Coach USA's strategy has been to acquire platform operations in key convention and gateway entertainment cities. This consolidation includes both motorcoaches and taxicabs. Coach USA is reluctant to acquire physical property in its acquisitions, so in many purchase agreements a separate entity is formed to own buildings that could then be leased back to them.

The major emphasis in Coach USA's strategy was purchasing established companies in large markets across various geographic regions (Business Journal, 1996). Coach USA had value for potential suitors because it positioned itself as a company with a broad geographic presence. Coach's strategy was to purchase family businesses with revenues of between $\$ 20$ million and $\$ 40$ million. The average age of the companies purchased was close to 40 years. Coach USA sought to retain the experienced managers in these companies for the short-term. Many of the initial acquisitions had five-year employment agreements with the previous owners.

In June 1999, Coach USA was acquired by Stagecoach, a Scottish company that was involved in public transportation consolidation on a worldwide basis. In addition to running trains and buses in the U.K., Stagecoach had companies in Australia, Finland, Portugal, New Zealand, and Hong Kong and owned a stake in a Chinese toll road company (www.stagecoachplc.com).

Similar to the strategy employed by Coach USA, Stagecoach had grown through acquisitions and is considered the largest consolidator of transportation companies in Britain. Stagecoach's purchase of Coach USA was viewed as a means for Stagecoach to enter the fragmented U.S. motorcoach market and a vehicle for further acquisitions in the U.S. (Apte, 1999).

When Stagecoach bought Coach USA, many of the previous owners who had made their family businesses successful were choosing to leave because they were no longer making the managerial decisions for their companies and/or their employment agreements were ending. In some cases, owners had been forced out due to regional consolidation within Coach USA. This had resulted in the loss of experienced operators managing some of their companies. In 2001, Stagecoach was forced to write down its investment in Coach USA (Jowit, 2001) and cut its forecast in half (Osborne, 2001). Recently, Coach USA has experienced restructuring due to estimated revenue shortfalls of $\$ 15$ million after September 11 (www.stagecoachplc.com).

\subsection{Laidlaw}

The second largest consolidator in the motorcoach industry is Greyhound (a predominantly line haul company). Greyhound Bus lines which was founded in 1914, has operated independently in the U.S. since it was spun off from Dial Corp. in March of 1987. A few months after the spin off, Greyhound bought its only nationwide competitor, Trailways Inc. Since then, Greyhound has been the only national bus line with route coverage in the U.S. serving more than 2,600 destinations with 18,000 daily departures (Fairbank, 1998).

Laidlaw, a Canadian company became interested in Greyhound because it complemented part of its core business which was school bus transportation, intercity, and public transit and tour services. Despite Laidlaw's Canadian roots, the company conducts over $90 \%$ of its business in the U.S. In March 1999 Laidlaw purchased Greyhound Lines at the peak of the consolidation phase in the U.S. (Fairbank, 1998). Laidlaw felt that this acquisition would achieve cost savings in vehicle purchase, insurance, financing and office costs. Laidlaw also planned to expand Greyhound's small charter and tour bus business by making acquisitions in a fragmented market and marketing its brand name (De Santis and Tomsho, 1998).

Laidlaw is also a major provider of school bus transportation and has a dominant presence throughout the U.S. in school bus operations. School buses provide a constant flow of dollars throughout the school year and can be used to supplement "low seasons" in the motorcoach part of the business. Many motorcoach owners provide school bus transportation as part of their business. 
Laidlaw is a diversified company that has experienced negative cash flow from parts of its operations. Buses have resulted in positive revenue flows for Laidlaw, but its broad business strategies have created severe financial problems. Revenues for Laidlaw during fiscal 2000 increased $7.6 \%$ to $\$ 1.428$ billion for school bus transportation and increased $60.2 \%$ to $\$ 1,498$ billion for intercity, public transit and tour services. Its losses in other areas led to a $\$ 3.4$ billion U.S. debt problem and resulted in Laidlaw stock trading at 12.5 cents by January 2001 compared with $\$ 22$ in early 1998 (Westell, 2000). Laidlaw explained its difficulties in its broad business as a result of losses on discontinued health-care operations and on bankruptcy - with possible accounting irregularities - of its Safety Kleen Corp. hazardous-waste unit (Phillips, 2000).

\subsection{VECTour Inc.}

The third largest motorcoach consolidator, VECTour Inc., began as Travelways in May 1997, as an entertainment and sightseeing company. They were also involved in selling rail tours and had airport routes. By October 1999, Travelways had acquired over 25 independent tour companies with revenues exceeding $\$ 150$ million. It had 800 motorcoaches and more than 300 town cars, vans and limos based at 46 facilities in 12 states (www.VECTour.com).

In December 2000, Travelways became VECTour Inc., a transportation and tour creation company. VEC Tour has a broad geographic base in the U.S. and operates using a decentralized approach from 19 locations with headquarters in Blue Bell, PA (www.VECTour.com). Each company in VECTour Inc. has its own rules for working with agents, commissions or quoting net rates. VECTour's strategy has been to grow internally as a privately held company.

VECTour Inc. focuses on selling domestic motorcoach tours and tours to international areas which is a different market segment than the one served by Coach USA or Greyhound. Similarly, all consolidators provide charter services. Due to its reliance on the tour segment, VEC Tours Inc. filed for Chapter 11 on October 17, 2001, claiming that they had experienced a 50\% drop in travel after September 11.

\section{Consolidator Business Practices}

Consolidation by the three largest players was at first thought to develop economies of scale due to centralized management and operating efficiencies. The gains accrue in centralizing functions such as finance, administrative support, purchasing power and a national sales and marketing program. Expected gains included obtaining competitive advantages and cost savings through group purchasing power, discounted group insurance, longdistance telephone, customer referral as well as global marketing and advertising efforts. Consolidators also planned to gain by brand recognition. The trademark (e.g., Coach USA or Trailways) provides international recognition while retaining local, state or regional company names and identities.

In reality, the overall financial performance has not been superior to the independent operators and regionally managed consolidators have not best served the interests of customers in developing on-going relationships. A common practice with consolidators is to allow the companies to remain under local control with no immediate changes in name, employees, or management. However, many experienced owner/operators are no longer in the business as they were bought out and left the business or completed their short-term employment contracts with regional managers now making the operating decisions for the firms. Two of the three major consolidators have filed for Chapter 11 protection.

Consolidators may have some minor advantages over small operators when mass movements are being made. Much of the growth in the motorcoach industry is due to the demand for large-scale events such as major sporting events. Consolidators have several motorcoaches at their disposal as they may own several companies within a geographic region. Consolidators actively seek out mass movements such as convention trade that requires many motorcoaches providing transportation for participants from hotels to convention facilities and to dinner and entertainment facilities. Consolidators, like Coach USA have attempted to capitalize on this market, but in huge movements even consolidators rely on the experienced owner/operators in that area. It is costly to bring in motorcoaches from other regions for short-term events when local motorcoaches are available. 


\section{Private Owner/Operators - How Have they been affected by the Change?}

The motorcoach business requires long hours including weekends with enormous capital expenditures. New motorcoaches cost approximately $\$ 400,000$. Pre-deregulation profits in the industry averaged $15-20 \%$ so there was financial incentive to stay in the business despite the huge investment. Low cost financing programs permitted an exchange of equity for cash flow and owners would purchase new or newer equipment to update fleets that provided a competitive advantage and generated depreciation write-offs.

Many motorcoach operators have sought to retain and grow their businesses by offering superior service and consistency in management leading to the development of on-going relationships with their customers. Relationships are difficult to maintain by the consolidators as management changes and decisions are made at the regional or national levels.

Many motorcoach businesses receive cross-subsidies from other internal businesses. Some owners subsidize their motorcoach business by providing mechanical services or have school bus operations that provide a guaranteed revenue stream. These revenues can be used to subsidize the motorcoach division during their "slow" season. Companies that depend on charter work are reliant on outside calls or contracts in which they provide pricecompetitive bids. On many occasions, owner/operators will be "sold out" of their equipment on the weekend, getting back-ups from other companies and will then struggle with overcapacity (i.e., unused motorcoaches) during the week. Private owner/operators will develop working relationships with other companies in their geographic area and help one another out when they are overbooked. This practice, in part, parallels the sharing of motorcoaches by the consolidators when mass movements are involved.

\section{What Do Owner/Operators See as the Major Concern Confronting their Industry Today?}

A survey was developed in order to ascertain the major issues confronting the motorcoach industry. Survey data was collected from 163 motorcoach owner/operators in January and February 2002 at the two national conventions for the industry: the United Motorcoach Association (UMA) and the American Bus Association (ABA). These two associations represent motorcoach industry owner/operators and provide advice and information regarding governmental requirements and changes to owner/operators as well as provide lobbying efforts on the industry's behalf.

The survey respondents represented all regions of the U.S. Forty percent of the 155 owner/operators who indicated a region on the survey were located on the East Coast, $39 \%$ of the respondents were from the Midwest, $14 \%$ of the respondents were from the South and $8 \%$ from the West Coast. Thirty-five percent of the respondents indicated that they were also involved in school bus operations, a corollary business.

\section{Spiraling Insurance Premiums is Major Problem in the Motorcoach Industry}

Motorcoach owner operators concluded that the major problem they are confronted with is spiraling insurance premiums. Of the 136 operators responding to this survey question, twenty-nine percent of the owner/operators ranked this as the number one concern that they are facing and an additional thirty-nine percent ranked it as number two. Insurance costs are increasing at an alarming rate often rising $35 \%$ or higher from the previous year. Many companies have limited their liability insurance reducing coverage from $\$ 10$ million to $\$ 5$ million, thereby accepting more risk in order to maintain their costs.

The impact of consolidators in reducing the number of carriers has led to increases in the private owner/operators insurance costs. O'Neill (2002) claims that there are several factors that have severely impacted bus insurers leading to price increases. Consolidators ended up eliminating about $\$ 20$ million to $\$ 25$ million in premium and reduced the industry's ability to spread risk. Driver shortages led to an increase in claim frequency because inexperienced drivers were involved in accidents at a significantly higher rate than more experienced drivers. Medical costs were escalating when accidents or injuries occurred. Due to higher claim costs, insurers began dropping buses as part of their provided coverage and focused on a different market segment (e.g., automobile coverage). Finally, reinsurers, large companies that insure those who insure the business, suffered after September 11 that resulted in a 
domino effect throughout the industry (Dolan, 2002).

Some motorcoach owners have responded to this insurance crisis by considering other insurance options. One option that has recently gained favor in the industry is the use of a captive insurance rather than a general insurance company. A captive insurance company is one that is essentially formed by members of a particular industry to cover that industry. Captive insurance companies provide an advantage in that they create stability in the pricing structure over time, rather than being subjected to gyrating costs in the industry. While general insurance companies may be lower during strong markets, captives are more consistent in price overall. Captive insurers know their industry so they are generally able to come up with effective loss control recommendations, which can reduce both the cost of losses and premiums. Captives will also offer expert witnesses and full litigation support whereas general insurance companies often have an adversarial relationship with their clients and give them minimal input in any settlement action (Dolan, 2002). This resulting claim loss can lead to higher insurance premiums in the future. It is estimated that one-third of the largest bus companies either have captive insurance or will be moving to captives in 2002 due to these benefits (Dolan, 2002).

Insurance in the motorcoach industry is based on the number of buses, average mileage, previous claims and geographic location. It is not an acceptable practice in the industry for owners to cancel insurance during low activity periods. This means that even during slower "off-seasons" the insurance is the same as during the working seasons and the costs must still be met. In addition to liability insurance, owner/operators are responsible for physical damage insurance that varies significantly by the value of the equipment. Insurance in this area has also been increasing by more than 50\%. Some companies have responded to this increase by increasing their deductible, thereby accepting greater risk.

This survey finding differs from previous studies where driver shortages have consistently been ranked as a number 1 problem in the industry (Kerckhoff, 2001). However, it is important to note that driver shortages contribute to the insurance cost problem. Depressed driver wages contribute to a high turnover rate in the industry and results in higher costs for owner/operators in the areas of training and recruiting. Newer drivers lack the experience of more seasoned drivers and are more prone to accidents that impact insurance rates. Other problems facing the industry as indicated by the motorcoach respondents include the business decline since September 11, the cost of new equipment, depressed trade in values on used equipment, driver shortages and the lack of maintenance support from manufacturers and suppliers.

The insurance crisis may act as a barrier for new entrants in the marketplace. New motorcoach entrants will experience more difficulty in meeting financial obligations due to increased insurance costs and financing difficulties that have engulfed the industry. For seasoned owner/operators this should mean fewer new competitors, but indicates the need for motorcoach operators to develop a strategy to cover their rising costs. This realization by motorcoach owner/operators may be one of the reasons that although the industry is experiencing a downturn, seasoned owner operators indicate that they are optimistic about their future. Sixty-one percent of the 153 respondents indicated that they feel that business will improve.

\section{Summary}

The motorcoach industry has changed very quickly and owner/operators are faced with the effects of consolidation and the declines in ridership due to the recent terrorist activity. Consolidation, which greatly changed the number of companies and operators in the industry, only represents about $10 \%$ of the industry and has not been the panacea in the marketplace nor the threat that independent owner/operators anticipated. The bankruptcy filings and downsizing by the consolidators may mean a more focused approach to establishing a strong market niche for their business in the immediate future.

What do these changes mean for individual owner/operators? Insurance costs need to be examined and consideration given to captive versus general insurance companies. There are some major advantages of captive companies and these should be explored before blindly continuing an existing policy. Owners should carefully examine their insurance claims and note patterns (e.g., individuals involved including age and experience, types of equipment, locations, time of day, accident causes) in order to determine how these claims can be prevented and ways to establish policies and procedures that will result in fewer claims in the future. Insurance premiums are de- 
pendent on previous claims.

Second, operating ratios for equipment needs to be carefully examined. Owner/operators should consider if their motorcoach business is self-supporting or is being subsidized bye related businesses. Are owner/operators charging enough to cover their costs? Simply keeping the equipment moving may not generate enough revenue to cover the costs associated with the business, particularly as costs are rising. Owners should examine usage levels and determine if the business they currently have warrants the expense of the number and type and/or size of their fleet and corresponding insurance costs. Operating ratios are beneficial for owners because they provide indicators that companies can use to benchmark themselves against. It can help them determine where they should apply their resources, how much money they should spend in particular areas such as maintenance and the revenue required to remain profitable. UMA has recently made this benchmarking information available to owner/operators in the industry (UMA, 2001).

Third, enhanced marketing efforts are needed when the industry is facing a downturn. A marketing plan is needed which will provide direction to the company and a focus on the niche that it is seeking. The owner/operator cannot find success in attempting to be all things to all customers. The owner/operator needs to decide who they are and what they do best in order to succeed. Due to the downsizing and consolidation that has occurred, owner/operators market reach can be expanded. It is critical to stress the importance of on-going relationships as that is a major distinguishing factor from the consolidators that have lost some of that experience and connections they had when they centralized their operations.

Finally, owner/operators should consider how they are spending their time. Are owner/operators running the business as a family business with the operator spending all of his time taking phone calls, maintaining equipment and driving the equipment or is the owner engaged in actively developing strategies for his business to succeed? Developing and re-evaluating a workable strategy is the most important job for an owner/operator in today's changed business environment.

\section{References}

1. American Bus Association (2000). Motorcoach Census Report, by Banks \& Associates.

2. Apte, Angela. (1999, June 18). "Acquisition of Coach USA offers U.S. growth for British company". Houston Business Journal, pp. 30(4), 6.

3. $\quad$ Business Journal (Phoenix) (1996, June 28). Coach USA Inc., pp. 16(35), 124B.

4. Culbertson, Katie. (1998, March 16). "City's cab king sold to Texas firm”. Indianapolis Business Journal, 18(53), p. 1.

5. De Santis, Solange, and Robert Tomsho, (1998, Oct. 20) "Laidlaw Agrees to Acquisition of Greyhound Accord for Cash and Stock Valued at $\$ 465$ million, plus debt assumption”, Wall Street Journal, p. A4.

6. Dolan, Thomas (2002, January). "It's "hard" times ahead for insurance market", Busride, pp. 32-36.

7. Fairbank, Katie, "Canadian company Laidlaw buying Greyhound Lines", Denver Post, Oct. 20, 1998, p. C-04.

8. Jowit, Juliette. (2001, March 3). "Stagecoach will write down US investment Transport pounds 200M Wiped off shareds after problems with Coach USA and UK Rail Business". The Financial Times (London), Companies and Finance, p. 14.

9. O'Neill, Randy (2002, January) "Insurance premium crunch created by the 'perfect storm'”, Metro Magazine, pp. 88-89.

10. Osborne, Alistair. (2001, March 3). "Stagecoach forecasts slashed by half". The Daily Telegraph (London), p. 31 .

11. Phillips, Don "Chance of Greyhound Failure 'Remote'; Parent Seeks to Explain Troubles to U.S. Agency" The Washington Post, Sept. 8, 2000, p. E2.

12. Schulz, John D. (2001, February 26). "The bus is always there; ABA chief Pantuso touts availability, flexibility of motor coach freight option". Traffic World, p. 33.

13. Starcic, Janna, (2002, January), "Coach USA Reclaims No. 1 spot in Top 50 Fleet Survey", Metro, p. 16-22.

14. United Motorcoach Association (2001) Benchmarking Study. 
15. United Motorcoach Association (2001b). State of the Industry Report

Notes 